Opinion

\title{
Do time and universe have the same age?
}

\section{Keywords: time, universe}

\section{Opinion}

Time represents a curtail concept in physics. Every physical (as well as chemical) changes such as movements (change of position) or reaction (change of status or structure) requires an amount of time as per both classical ${ }^{1}$ and quantum mechanics. ${ }^{2}$ Since time is a central parameter in physics, its quantification would have consequences and impacts not only on daily studies physical changes but also to date and estimate the universe-scale period of change. Consequently, impact the period estimations as the period is defined as the difference between two time points such as the beginning and the end of an event.

Importantly, quantification of the time remains relative and depend of comparisons. Indeed, for instance a period of 24 hours is defined as the amount of time required for the planet of earth to complete a rotation around itself, one year is defined as the periods required by the earth to make a rotation around the sun, one month is defined as the periods required by the moon of earth to make a rotation around the planet earth, etc. This examples illustrate how the time quantifications was establishes starting from the old civilization such as Maya civilization and ancient Egypt, a quantification which is by definition relative to how fast (in our examples) moon and earth move in their orbits.

Therefore, if for instance earth and moon were stable (no positioning changes) we would have had to take another "reference for time" such as other moving planets. But, if we supposed we have no planets, we would in this case need to define the difference between two time points (amount of time) as the period required to accomplish a change by a physical entities that we would have selected.

Just as an illustration, we could have selected to define one day as the time required by stone thrown form a certain altitude and under defined conditions to reach the floor. Following this line of thoughts, it is not only the changes that depend on time but the time definition and estimation also depend on the existence of physical changes or variation. Thus, if no changes exist there would be no such definition. This means that the existence of the time depends on the existence of a physical entity undergoing changes.

Therefore, before the universe appears, there were no planets and no other physical entity that could undergo change, and thus, no relative
Volume 4 Issue 6 - 2020

\author{
Abdelaziz Ghanemi \\ Laval University, Canada \\ Correspondence: Abdelaziz Ghanemi Laval University, 2325, \\ rue de l'Université, Québec (Québec) GIV 0A6, Canada, \\ Email abdelaziz.ghanemi.।@ulaval.ca \\ Received: December 2I, 2020 | Published: December 3I, \\ 2020
}

measurement to quantify time. As a conclusion, it seems logical to say that the time is a consequence of the universe appearance. Before the universe appeared, there were no physical entity, therefore no existent physical changes to be used as a reference to quantify the time as those changes go. Therefore, the universe and the time would have the same age.

\section{Acknowledgments}

Abdelaziz Ghanemi is a recipient of a Merit scholarship program for foreign students from the Ministry of Education and Higher Education of Quebec, Canada, The Fonds de recherche du Québec - Nature et technologies (FRQNT) is responsible for managing the program (Bourses d'excellence pour étudiants étrangers du Ministère de l'Éducation et de l'Enseignement supérieur du Québec, Le Fonds de recherche du Québec - Nature et technologies (FRQNT) est responsable de la gestion du programme).

\section{Conflicts of interest}

None (The author declares that there is no conflict of interests).

\section{References}

1. Günther B, Morgado E. Time in physics and biology. Biol Res. 2004;37:759-765.

2. Vaccaro JA. The quantum theory of time, the block universe, and human experience. Philos Trans A Math Phys Eng Sci. 2018;376. 